\title{
Le Roman de Thèbes, Édition bilingue. Publication, traduction, présentation et notes par Aimé Petit
}

\section{Maria Colombo Timelli}

\section{(2) OpenEdition}

\section{Journals}

Édition électronique

URL : http://journals.openedition.org/studifrancesi/5518

DOI : 10.4000/studifrancesi.5518

ISSN : 2427-5856

Éditeur

Rosenberg \& Sellier

\section{Édition imprimée}

Date de publication : 1 septembre 2011

Pagination : 382

ISSN : 0039-2944

\section{Référence électronique}

Maria Colombo Timelli, «Le Roman de Thèbes, Édition bilingue. Publication, traduction, présentation et notes par Aimé Petit », Studi Francesi [En ligne], 164 (LV | II) | 2011, mis en ligne le 30 novembre 2015, consulté le 10 janvier 2021. URL : http://journals.openedition.org/studifrancesi/5518; DOI : https:// doi.org/10.4000/studifrancesi.5518

Ce document a été généré automatiquement le 10 janvier 2021.

\section{(c) (†) $\ominus$}

Studi Francesi è distribuita con Licenza Creative Commons Attribuzione - Non commerciale - Non opere derivate 4.0 Internazionale. 


\title{
Le Roman de Thèbes, Édition bilingue. Publication, traduction, présentation et notes par Aimé Petit
}

\author{
Maria Colombo Timelli
}

\section{RÉFÉRENCE}

Le Roman de Thèbes, Édition bilingue. Publication, traduction, présentation et notes par Aimé PETIT, Paris, Honoré Champion, 2008 («CCMA», 25), 677 pp.

1 C'est un des grands spécialistes des romans d'Antiquité qui s'est chargé de cette édition bilingue du Roman de Thèbes. Comme on pouvait s'y attendre, l'Introduction est dense: elle fait le point sur toutes les questions fondamentales - philologiques, linguistiques, littéraires-qu'exige une approche sérieuse du texte, et rendra service tant aux médiévistes chevronnés qu'aux non-spécialistes. Aimé Petit présente d'abord la tradition manuscrite de Thèbes ( 5 manuscrits plus les «fragments d'Angers») et les éditions modernes (L. Constans 1890; D. Phelps Ripley, PhD Thesis 1960; G. Raynaud de Lage, 1966-1968; F. Mora-Lebrun 1995), pour s'arrêter plus longuement sur le manuscrit BnF fr. 784, le plus ancien des manuscrits complets (copié entre 1230 et 1270), base de l'édition de Lage, alors que F. Mora s'était fondée sur le ms. Londres, B.L. Add. 34114. Même si la date et l'auteur du Roman de Thèbes constituent toujours un "problème insoluble» (p. 20), A.P. ne renonce pas à présenter ce que l'œuvre elle-même nous révèle quant à la datation relative, à la culture de l'auteur, au milieu de production, questions des plus discutées par les critiques du dernier siècle. Les aspects littéraires font l'objet d'un chapitre intéressant où sont traités les rapports avec la source latine, avec les autres genres littéraires du Moyen Âge - notamment la chanson de geste - et avec quelques évènements contemporains, tels la Première Croisade. Le paragraphe consacré à la naissance du roman, autre domaine privilégié dans les recherches d'A.P., rappelle synthétiquement quelques caractéristiques majeures de Thèbes: l'anachronisme, l'importance de l'amour et des portraits, surtout féminins, ainsi que 
certains phénomènes stylistiques et rhétoriques. Quelques pages concernent encore la postérité de l'œuvre, mentions éparses ou allusions plus certaines, tant en France jusqu'à Christine de Pizan-qu'à l'étranger, en particulier chez Chaucer et John Lydgate.

2 Après l'Analyse, quasiment indispensable pour se retrouver dans un roman d'une telle ampleur (10562 vers, dans cette rédaction), on trouvera une note sur la traduction, où sont discutés des problèmes tant généraux que spécifiques d'un texte qui dérive d'une source classique: alternance des temps verbaux ou de tu / vous au sein d'une même réplique de dialogue, répétitions voulues, mais aussi onomastique. A.P. a assumé le choix d'une traduction d'«allure un peu archaïsante» (p. 62), qui ne nuit pas au texte, et qui, bien au contraire, permettra aux non-médiévistes de saisir quelque peu son caractère original. La Bibliographie, pp. 65-75, constitue un complément d'une grande utilité.

3 L'édition publiée est celle de Raynaud de Lage, «avec quelques modifications» (p. 54, mais p. 10 on parle d' «une toilette complète du texte»), accompagnée de la traduction en français moderne et de notes en bas de page; à quelques détails près, la traduction est celle qu'Aimé Petit a publiée en 1991 pour les «CFMA». En annexe: les leçons du manuscrit de base rejetées, l'Index des noms propres (qui intègre les renvois à leur première apparition dans la Thébaïde) et le Glossaire. 